\title{
O ENSINO DE HISTÓRIA NO ENSINO MÉDIO EM ESCOLAS INTEGRANTES DO PROGRAMA UNIVERSIDADE-ESCOLA DA UNOCHAPECÓ
}

\section{THE HISTORY TEACHING IN THE HIGH SCHOOL THAT PARTICIPATE IN THE UNIVERSITY- SCHOOL PROGRAM OF UNOCHAPECÓ}

\author{
Elison Antonio Paim ${ }^{1}$ \\ Alan Kaufmann de Mattos \\ Anderson Poli \\ Anderson Silva \\ Aline Maisa Lubenow \\ Álisson Domingos Prior \\ André Detoni \\ Daniel Dalla Zen \\ Eny D. Pereira \\ Raquel Reis \\ Regina Daiana Chiesa \\ Rodrigo Brivio ${ }^{2}$
}

RESUMO: O presente texto expressa alguns resultados da pesquisa "O ensino de História no Ensino Médio em Escolas Integrantes do Programa Universidade-Escola da Unochapecó", desenvolvido pelo coordenador de estágio e acadêmicos do sétimo período do curso de História. A pesquisa buscou compreender como os alunos se relacionam com a disciplina de história e qual importância a ela atribuída. O foco da pesquisa foram alunos de escolas públicas de Santa Catarina e Rio Grande do Sul conveniada com a Universidade Comunitária da Região de Chapecó (Unochapecó) para campo de estágio. A busca dos dados ocorreu por meio de questionário, com questões abertas e fechadas, respondido por alunos de cada turma na qual seriam desenvolvidas as atividades de estágio docente no semestre seguinte.

Palavras-chave: Ensino de História. Estágio. Ensino Médio.

\begin{abstract}
This text shows some results of the research "The History Teaching in the High School that participate in the University- School Program of Unochapecó", developed by the internship coordinator and the seventh phase history academics, which tried to understand how the students relate with the discipline history and what is it importance. The research focus was the public schools students in Santa Catarina and Rio Grande do Sul which had internship agreement with the university. The data search happened through open and closed questions questionnaires that was answered by students of each class where there would be developed academic internship activities in the next semester.
\end{abstract}

Keywords: History Teaching. Internship. High School.

\footnotetext{
${ }^{1}$ Doutor em Educação pela Universidade Estadual de Campinas (Unicamp). Professor no curso de História da Universidade Comunitária da Região de Chapecó (Unochapecó).

2 Graduados em História, Licenciatura Plena, pela Universidade Comunitária da Região de Chapecó (Unochapecó)
} 


\section{Para Iniciar: Algumas Considerações Sobre Pesquisa e a Pesquisa em Pauta}

No que se refere à relação ensino e pesquisa, há de se considerar os desafios e as contradições que querem explicitação, uma vez que de um lado encontravam-se/encontram-se os pesquisadores, enquanto detentores de um saber acumulado, distantes dos espaços educativo/institucionais e do outro lado encontravam-se/encontram-se os professores, detentores de saberes experienciais, eivados por práticas reflexivas, de problematização, atentos a uma concepção de conhecimento enquanto produção humana, histórica e culturalmente desenvolvida.

Neste contexto, Lenoir (2006, p.1303) sinaliza que se fazem necessárias algumas distinções conceituais, para compreender o procurar e o pesquisar. Destaca que: "Procurar, do latim procurare, significa ação, o esforço para achar ou descobrir alguma coisa. A palavra "pesquisar", quanto a ela, coloca em evidência duas dimensões fundamentais que devem acompanhar uma investigação sistemática: o trabalho de reflexão e o esforço de investimento que requer uma pesquisa".

Adensando sua reflexão Beillerot (1991), apresenta alguns indicadores ao uma distinção do ponto de vista científico entre "estar em pesquisa" e "fazer pesquisa". Para este autor estar em pesquisa, é refletir sobre os problemas, sobre as dificuldades encontradas; é se esforçar em descobrir respostas a questões que colocamos. Trata-se, diz ele, de uma reflexão sobre nossas práticas e nossas experiências, as quais seguramente são visualizadas sob diferentes perspectivas. Tanto o pesquisador quanto do professor diferem por conta das incursões que realizam.

Ainda, de acordo com Lenoir (2006), fazer pesquisa do ponto de vista científico repousa em outros alicerces, assim como evidencia Beillerot (1991, p.19) "fazer pesquisa implica outros processos, notavelmente aqueles que impõem o verbo "fazer": encontrar os meios de uma objetivação das questões e das preocupações para poder estudá-los". Para ele fazer pesquisa de "primeiro grau" implica em três questões fundamentais: - uma produção de novos conhecimentos (critério no. 1); - 
um processo rigoroso de investigação (critério no. 2); a comunicação dos resultados (critérios no. 3).

Acreditamos que os critérios citados por Beillerot, são apenas indicadores, não parâmetros. Até porque mais do que nunca, a prática efetiva da sala de aula constituiu-se num desafio, isento de idéias prescritivas. Assim sendo a inovação, a inserção da prática de pesquisa demarcada pelas reflexões e pelas análises critico/propositivas, tem-se constituído num espaço de formação diferenciado que exige sistematicamente a presença do professor do pesquisador e do professor/pesquisador.

Entre os múltiplos desafios referenciados pela prática da pesquisa via iniciação científica nos cursos de graduação em licenciatura, temos a comunicação oral e escrita, a capacidade de síntese, o exercício da procura sistematizada e a atitude investigativa. Em razão disso a iniciação científica deve apoiar-se nas linhas de pesquisa, definidas pelos grupos de pesquisa, incubadores naturais, as quais devem auxiliar no desenvolvimento da investigação. É oportuno enfatizar que a busca do conhecimento científico é um processo argumentativo que se explicita no conflito, mas que tem que ser ético e socialmente comprometido com a educação.

Assim, a pesquisa para Demo (1998), indica a necessidade de a educação ser questionadora, do indivíduo saber pensar com autonomia e se emancipar, através de sua consciência crítica e da capacidade de fazer propostas.

Independentemente do curso o projeto político pedagógico das graduações da Unochapecó, dão relevo as habilidades a serem desenvolvidas para o desenvolvimento da pesquisa procurando desenvolver a tessitura da relação entre ensino e pesquisa.

Contudo vale destacar que apesar das fragilidades evidenciadas, cotidianamente temos possibilidades que emergem desse contexto, amparadas na precursora concepção de Paulo Freire, o qual evidencia que pensar sobre a própria prática é a melhor maneira para se pensar certo. Considerando que o processo de formação de professores nos cursos de licenciatura da Unochapecó, tem sido marcado por diferentes incursões, neles foram e são desenvolvidas pesquisas no ensino, sobre o ensino e a 
partir de reflexões que os professores fazem sobre o quê e como ensinam. Neste sentido, nossos feitos vêm de encontro ao que Carvalho (2002) sistematiza; um processo de reflexão sobre a formação docente atento as especificidades das pesquisas no ensino, atentas à melhoria da qualidade de aprendizagem, amparado em reflexões sobre os diferentes fazeres dos professores em formação.

Nesse sentido, o curso de Licenciatura em História da Unochapecó historicamente tem procurado desenvolver atividades que possibilitem aos acadêmicos problematizar as suas e as praticas dos professores com os quais passam a ter contato durante suas incursões nas escolas pelas atividades de Prática de Ensino de observação e docência na Educação Básica.

As Práticas de Ensino do curso de História estão estruturados em cinco semestres letivos. Na primeira experiência os acadêmicos fazem sua primeira incursão na escola, quando desenvolve atividades de observação, entrevistas, questionamentos e contatos com sua estrutura pedagógica e administrativa. No segundo momento, os acadêmicos começam adentrar nas especificidades do ensino de História realizando um estágio de observação de aulas de história em uma turma de Ensino Fundamental na qual, no semestre seguinte, desenvolverão a docência. Na terceira experiência desenvolverão a docência na turma observada no semestre anterior. No quarto semestre de estágio os acadêmicos deverão realizar a observação de aulas de história no Ensino Médio. No quinto semestre de Prática de Ensino/estágio os acadêmicos desenvolvem a docência em turmas do Ensino Médio.

Após a realização de três momentos de contato com as escolas, observação e docência no Ensino Fundamental os acadêmicos do sétimo período do curso de História da Unochapecó, durante o primeiro semestre de 2010, decidiram que, para além das atividades costumeiras de um estágio de observação, queriam fazer uma pesquisa para compreender melhor o ensino de história na percepção dos alunos do Ensino Médio. Depois de muito debatermos os prós e contras acordamos que trabalharíamos em grupos para a produção do projeto de pesquisa para levantamento de informação. Para tanto, cada grupo deveria escrever uma 
parte. Após a escrita de uma primeira versão, cada grupo expôs para o grande grupo o que havia escrito. Debatemos e complementamos coletivamente de forma a dar organicidade e unidade. Definimos que a coleta de dados seria realizada por intermédio de um questionário, com questões abertas e fechadas, que seria respondido por $20 \%$ dos alunos de cada turma onde correriam os estágios de observação. A escolha dos respondentes deveria ser de forma aleatória.

A pesquisa foi realizada em instituições de Ensino Médio integrantes do programa Universidade-Escola. Este programa constitui-se de um convênio entre a Unochapecó e as escolas campo de estágio no qual estas possibilitam a realização de estágios em diferentes áreas do conhecimento e, em contrapartida, a universidade oferece curso de formação continuada aos professores de Educação Básica. Todas as escolas integrantes da pesquisa são da rede pública estadual do Rio Grande do Sul e Santa Catarina.

Responderam o questionário entre quatro e seis alunos por turma, totalizando 57 entre as 11 turmas dos três anos onde aconteceram os estágios.

As perguntas foram distribuídas em blocos temáticos com número variável de questões em cada um, distribuídas em: dados de identificação; o ato de estudar; metodologias; e a disciplina de história.

Após a coleta dos dados, cada grupo ficou com um dos blocos de questões a serem tabuladas, categorizadas e analisadas. Na sequência, realizamos o diálogo com autores que vem produzindo sobre o ensino de História. Durante os horários de aula passamos a trabalhar diretamente no laboratório de informática.

\section{Situando as Escolas e os Alunos}

A partir do contato dos estagiários com o Projeto Político Pedagógico (PPP), caracterizamos brevemente alguns aspectos de cada uma das 
escolas e sua distribuição geográfica. Os dados apresentados sobre elas são de 2010, ano de realização da pesquisa.

No município de Chapecó trabalhamos com três escolas. A Escola de Educação Básica Coronel Lara Ribas, com aproximadamente 1,2 mil alunos. Trabalham na instituição 52 pessoas, entre docentes e diretores, possui 16 salas de aula. A Escola de Educação Básica Professora Zélia Scharf que tem aproximadamente 1,8 mil alunos. Em 2010 eram 89 pessoas, entre funcionários, professores efetivos, professores Admitidos em Caráter Temporário (ACTS) e diretores, que lá trabalhavam. A Escola de Educação Básica Professor Nelson Horosteck, com 971 alunos, possuía 52 trabalhadores.

No município de Xaxim, Santa Catarina a Escola de Educação Básica Neusa Massolini tem aproximadamente setecentos alunos e trinta pessoas no corpo docente, no administrativo e funcionários de serviços gerais.

No município de Caibi, em Santa Catarina, trabalhamos com a Escola de Educação Básica Dom Pedro II, que tem aproximadamente 751 alunos e 45 funcionários.

No município de Pinhalzinho, em Santa Catarina, Escola de Educação Básica Vendelino Junges. A escola tinha 350 alunos e vinte funcionários.

A Escola de Educação Básica Raimundo Corrêa, no município de Seara, em Santa Catarina. Contava com aproximadamente setecentos alunos.

No município de Planalto, estado do Rio Grande do Sul, foi pesquisado a Escola de Educação Básica Padre Vitório. Integrante da rede pública estadual de educação, a escola tinha 885 alunos matriculados e 63 funcionários.

A pesquisa envolveu onze turmas do Ensino Médio, divididas entre os três anos: foram três turmas do primeiro ano, quatro do segundo ano e quatro turmas do terceiro ano. Os turnos se concentraram entre o matutino e vespertino, contando com cinco turmas de cada e apenas uma noturna. Vale lembrar que a escolha dessas turmas aconteceu devido à disponibilidade dos acadêmicos-pesquisadores em desenvolver seus estágios sob a influência de fatores como a disponibilidade de tempo, turno 
livre e a pré-escolha das turmas feitas pela Gerência Regional de Educação da Região de Chapecó (Gered), para que se estabelecesse este perfil das turmas nas respectivas escolas.

Responderam ao questionário 57 alunos, sendo 22 meninos e 35 meninas. Do total de questionários, pudemos considerar 56 respostas, pois um dos entrevistados não levou em conta a seriedade da pesquisa e a importância em responder corretamente as questões propostas; acabou anulando parte do seu questionário.

A maioria dos alunos respondentes reside na zona urbana, somando 45. Os outros 12 residem na zona rural. Acrescentando, ainda, que 22 deles fazem uso do transporte coletivo, seis possuem transporte próprio e 29 não fazem uso de nenhum desses recursos, pois provavelmente deslocam-se a pé para as escolas.

Uma boa parcela dos alunos trabalha. Analisemos, então, os resultados obtidos: nove encontram-se desempregados; os que se consideram a procura de emprego somam seis; os que estão deixando o trabalho para mais tarde e priorizando os estudos são vinte; e os que estão empregados somam 16. A este grupo podemos adicionar mais seis que responderam que desenvolvem trabalho familiar. Portanto, temos 22 alunos que dividem parte do seu tempo entre a escola e outra atividade. Alegam que têm como objetivo ajudar a família ou a sua própria independência financeira frente aos seus gastos com transporte, vestuário, passeios e objetos de uso pessoal.

Os respondentes ao questionário trabalham em atividades como secretárias, garçons e auxiliares, correspondente a programas de colaboração do governo, com as empresas locais e escolas, como é o caso do programa Jovem Aprendiz. Existem ainda os jovens que trabalham com suas famílias, sendo que essa condição se traduz tanto aos jovens que moram na zona urbana quanto os jovens que moram na zona rural que trabalham junto de seus pais em atividades agrícolas.

Atividades realizadas dentro do próprio domicilio influenciam menos no desempenho escola do que as atividades remuneradas desenvolvidas em estabelecimentos exteriores. Tal situação nos remete para um dado 
relevante, pois o estudo apontou que a maioria desses jovens trabalha por mais de sete horas diárias. Desta forma, coloca-se em risco a qualidade do ensino e da aprendizagem, contrariando o que prevê o Estatuto da Criança e do Adolescente que aponta a idade mínima para o trabalho como 16 anos, liberando os indivíduos maiores de 14 anos para atuar apenas na condição de aprendizes.

Quanto à renda familiar, podemos observar que o maior grupo concentra-se naqueles que possuem dois a quatro salários mínimos, sendo vinte famílias; temos 13 famílias que somam de quatro a seis salários; dez famílias com renda menor que dois salários mínimos; as famílias que ganham acima dos dez salários contabilizam oito e, de oito a dez salários mínimos são duas famílias. Portanto, a ampla maioria das famílias possui uma renda mensal entre dois e seis salários mínimos.

Destacamos ainda que 44 dessas famílias residem em casas próprias; dez moram em casa alugada e temos dois casos em que a residência foi cedida. Destacamos também a informação de que 55 desses alunos residem com seus pais e apenas dois moram com outras pessoas sem terem os pais como responsáveis.

Destaca-se o papel da família junto aos alunos, como já referido. Praticamente todos os alunos entrevistados residem e tem seus pais como responsáveis. Dessa maneira, podemos colocar a família como um elemento auxiliador e motivador para os alunos. Há de se destacar que para muitos a formação superior e a escolaridade são vistos como fundamentais para a inserção em uma nova camada social, bem como a estabilidade financeira e o status que isso promove de fato. Esse é um pensamento fortemente difundido principalmente na América do Sul, como aponta Hobsbawm: "Dos estudantes latino-americanos entrevistados por pesquisadores americanos em meados da década de 1960 em vários países, entre 79\% a 95\% estavam convencidos de que o estudo os colocaria numa classe social superior dentro de dez anos". (HOBSBAWM, 1995, p. 291).

Contemplamos algumas informações que são de suma importância para quem realiza atividades ou pretende realizar atividades com alunos do Ensino Médio. Da mesma forma que se afirmam dentro do cenário da 
educação brasileira, os jovens pertencentes a esse grupo também estão em processo de afirmação, fato este demonstrado principalmente por vários deles estarem no mercado de trabalho e com um número significativo de jovens que trabalham em serviços exteriores às unidades familiares. Assim, podemos intuir que os jovens, hoje, pertencentes ao Ensino Médio, já podem ser classificados como sujeitos economicamente ativos dentro da sociedade em que estão inseridos.

\section{O Ato de Estudar}

Ao questionar os alunos sobre o gosto pelo estudo, foi possível constatar que $73,70 \%$ responderam que gostam de estudar. Apresentaram como justificativa o pensamento no futuro, para terem oportunidades melhores de emprego, pois para eles, a educação é essencial para a vida, auxilia na formação do caráter. Dentre as respostas selecionamos duas respostas que expressam o pensamento geral: "Gosto de ler e estar sempre ligado com o que acontece no cotidiano" e "Gosto, mas depende da matéria, tem matéria que eu não gosto de estudar".

Aqueles que responderam não gostar de estudar atingiram 5,26\%, tendo como justificativa que: "Muitas vezes é cansativo"; "mas precisa no futuro, ela deverá estar presente na função que irá exercer" e "às vezes, as aulas são chatas e fazem com que os alunos se dispersem dos objetivos".

Uma parcela das respostas foi que gostam ou não de estudar dependendo da situação. Estes somam 19,30\%. As respostas giram em torno da concepção que o professor poderia deixar a disciplina ruim, que o próprio conteúdo era chato ou ainda variando seu gosto ou não centrado no fato de ter ou não prova.

Ao perguntarmos qual a percepção da importância do ato de estudar, $98,24 \%$ afirmaram ser importante. Justificam por exemplo, que é importante estudar: "Porque hoje pra tudo você precisa de conhecimento, o mundo requer isso de cada um para irmos bem em todos os campos da nossa vida". 
Segundo os dados coletados, quando questionados sobre qual a sua disciplina preferida, $15,80 \%$ dos alunos responderam Educação Física. Como justificativa apontaram a questão da prática de esportes e diversão e, também, o fato de não estarem dentro de uma sala de aula. Além da Educação Física, apareceram como disciplinas favoritas: Matemática, História e Biologia, com 12,28\%; Filosofia, com 8,87\%; Português, com 7,20\%; Geografia, com 7\%; Física, Inglês e Artes, com 5,26\%; Sociologia e Química, com 1,75\%. Apontaram com fatores de preferência "ser uma forma de expressão, estar ligada com a profissão que vai seguir no futuro, maior entendimento do planeta, para aprender ler e escrever corretamente, melhorar interpretação entre outros".

A partir desses dados, podemos fazer uma relação com o escrito de Paulo Freire, quando afirmou que:

Ao se estudar o comportamento do homem, a sua capacidade de apreender, a licitude do processo de sua educação, não é possível o esquecimento de suas relações com sua ambiência. Disto ressalta a sua inserção participante nos dois mundos, sem, todavia, a sua redução a nenhum deles. (FREIRE, 2001, p. 10).

Analisando os dados na relação com o pensamento de Paulo Freire, é nítido o interesse dos alunos somente pelas disciplinas em que percebem uma relação com a sua vida. Portanto, o professor não deve explicar seu conteúdo ou sua disciplina somente na teoria, mas procurar entrelaçar a teoria com a vida dos alunos, procurando mostrar qual é a importância de estudar tal disciplina para sua construção como cidadãos.

$E$, nesse sentido, que se pode afirmar que o homem não vive autenticamente enquanto não se acha integrado com sua realidade. Criticamente integrado com ela. E que vive vida inautêntica enquanto se sente estrangeiro na sua realidade. Dolorosamente desintegrado dela. Alienado de sua cultura. (FREIRE, 2001, p. 11).

Quando perguntamos qual a disciplina que menos gostam, os alunos responderam que é Matemática, 21,05\%; Física, 17,54\%; Química, 
10,53\%; Sociologia, 8,77\%; Filosofia e História, 7,01\%; Português, Geografia e Educação Física, 5,26\%; Biologia, 3,53\%; Inglês, 3,50\%; Artes, $1,75 \%$. Sobre as justificativas apontaram "que não entendem a disciplina"; "não há utilidade"; "não compreendem; sem afinidade"; "aulas cansativas e sempre a mesma aula repetitiva" e "não serve para carreira futura".

Este desinteresse dos alunos por certas disciplinas, ou até mesmo de estudar, pode ser explicado por Freire, quando nos indaga:

Como [...] aprender a discutir e a debater numa escola que não nos habitua a discutir, por que impõe? Ditamos idéias. Não trocamos idéias. Discursamos aulas. Não trabalhamos com ele. Impomos-lhe uma ordem a que ele não se ajuste concordante ou discordantemente, mas se acomoda. Não lhe ensinamos a pensar, por que recebendo as fórmulas que the damos simplesmente as "guardas". (FREIRE, 2001, p. 90).

Percebemos uma grande relação com as justificativas elencadas pelos estudantes, pois os conteúdos só são transmitidos, sem debater ou sem problematizar, desconsiderando-se, portanto, os conhecimentos anteriores. Nesta relação, o professor e os alunos são apenas consumidores do conhecimento.

\section{Metodologias Utilizadas Para Ensinar História}

A metodologia do ensino como eixo central deste item está pautada na maneira como o docente ministra as aulas, neste caso, aulas de história. A metodologia mais utilizada no processo de ensino-aprendizagem relaciona-se diretamente com o livro didático. Porém, além do livro didático, há alguns anos os recursos didáticos, sendo alguns tecnológicos, vêm evoluindo. Como exemplo, citamos o data-show, que oportuniza ao docente colocar o conteúdo em slides e iniciar deste ponto as aulas, ou, então, a facilidade de encontrar mecanismos de reprodução de materiais que oportunizam ao professor trabalhar com textos, fontes, jornais e revistas na sala de aula. 
Relacionado os métodos citados acima, ao problematizarmos qual a metodologia mais utilizada em sala, foram encontradas resposta muito parecidas, apesar das instituições de ensino serem diferentes. A maior parte dos alunos relatou que a metodologia de ensino nas aulas de história mais utilizada é a leitura do livro didático, seguido da explicação do professor, que complementa a aula realizando atividades e exercícios. Neste contexto, mostraremos algumas das respostas dos alunos: "A gente le (sic) em voz alta e a professora explica a cada um ou dois parágrafos do livro"; "Ela utiliza mais os livros didáticos e não traz outras coisas para discutirmos"; "Ele lê o livro explica e assim manda passar no caderno o que nos entendemos" e "Explicação mais anotação mais leitura".

Em contraponto, algumas respostas mostram que as metodologias que norteiam a aula são à base de filmes, mapas, revistas e jornais, como as seguintes respostas: "A profe usa o livro às vezes, matérias que estão em jornais, revistas, mapas"; ou, ainda, leituras, mapas e filmes: "Às vezes a professora usa o livro e às vezes o filme".

Entre as várias formas de ensinar aparecem com maior frequência o livro didático e outros recursos, como discussões e debates. Bittencourt afirma que podemos observar um pouco dos objetos de uso que, com intermédio do professor, tornam-se meios para o processo de ensino aprendizagem:

Os suportes informativos correspondem a todo discurso produzido com a intenção de comunicar elementos do saber das disciplinas escolares. Nesse sentido, temos toda a série de publicações de livros didáticos e para-didáticos, Atlas, dicionários, apostilas, cadernos, além das produções de vídeos, CDs, DVDs e materiais de computador (CD-ROM, jogos, etc. [...] Os documentos, diferentemente dos suportes informativos, foram produzidos inicialmente sem intenção didática, almejando atingir um público mais amplo e diferenciado. Contos, lendas, filmes de ficção ou documentários televisivos, músicas, poemas, pinturas, artigos de jornal ou revistas, leis, cartas, romances são documentos produzidos para um público bastante amplo que, por intermédio do professor e seu método, se transformam em materiais didáticos. (BITTENCOURT, 2004, p. 296). 
Bittencourt divide os objetos que carregam informações entre suportes informativos, criados com intenção de proporcionar a produção de conhecimento didático, e em documentos, objetos criados sem intenções didáticas, porém, com intermédio do professor, tornam-se meios valiosos para se trabalhar em sala de aula. Alguns dos exemplos citados, nessa segunda classificação, vinculam-se como métodos complementares, mas há aqueles objetos que podem muito bem ter o papel central na aula.

Dentro do questionário procuramos levantar informações correspondentes ao uso de recursos didáticos em sala de aula, constatando que $77 \%$ dos alunos, dentre 57 questionados, responderam que o docente utiliza recursos como vídeos (filmes e documentários), livros, textos e mapas. Outros recursos também foram notificados, mas com menor frequência, como: data-show, laboratório de informática e música. Portando, entende-se que os docentes procuram diversificar os métodos como guiam as suas aulas de história durante um ano letivo.

Neste contexto, sobre os recursos didáticos utilizados em sala de aula, ressalta-se neste instante o livro didático, que pode ser considerado o principal instrumento que permeia o processo educativo. Portanto, o livro didático é amplamente utilizado em sala de aula pelo professor como uma ou, em muitas vezes, a única forma de trabalho.

A maioria dos alunos argumentou que o livro didático é utilizado para realizar leituras, exercícios, acompanhamento do conteúdo das explicações, análise de mapas, gravuras e documentos históricos. Apenas uma pequena parcela relatou que o livro didático não é utilizado em sala de aula ou, então, respondeu aleatoriamente a questão, como mostram algumas respostas dos alunos: "Para fazer trabalhos e para auxiliar, ver algum mapa, gravura"; "É utilizado principalmente para a análise de documentos históricos e atividades"; "Nós usamos em todas as aulas ele, pois quando ele explica conteúdos" e; "Ele utiliza para que os alunos leiam e depois o professor explica o conteúdo".

Diante destas respostas, constata-se que o livro didático auxilia nas explicações do professor, mas também possuem outros recursos didáticos, como imagens e mapas. Em suma, a ferramenta em discussão caracterizase como a metodologia mais empregada no desenvolvimento das aulas de 
história pelo professor. Deve-se destacar que em raros casos não é utilizado o livro didático nas aulas de história, observando a seguir as respostas coletadas em uma mesma instituição de ensino: "não usamos livro"; "por enquanto não usamos o livro" e "não é usado".

A partir das abordagens destacadas sobre as metodologias no ensino de História, cabe, neste momento, salientar como importante o domínio de conteúdo por parte do professor e a relação deste conteúdo com os alunos.

Deste modo, cabe ressalvar a importância dos saberes docentes (MONTEIRO, 2002) no processo de ensino-aprendizagem. De fato, o ensino é um campo de pesquisa em processo de constituição com necessidade da reflexão sobre os métodos teóricos e práticos. Dentre as respostas coletadas, $96 \%$ dos alunos responderam que o professor possui domínio do conteúdo por conduzir a aula de história com facilidade nos mais diversos assuntos estudados durante o ano. Outro aspecto que expressa o domínio de conteúdo é a capacidade de responder as dúvidas surgidas durante a aula, inclusive os alunos relatam que o professor possui boa oralidade, utilizando um vocabulário que facilita a compreensão. Dentre as respostas, destacamos: "Geralmente sim. Pois sempre responde nossas dúvidas e nos faz entender o conteúdo" e "Sim, porque quando ele está explicando ele demonstra que sabe o que está nos ensinando".

Em alguns casos, os alunos confundiram os termos "domínio de conteúdo" com a "metodologia de ensino" utilizada em sala de aula. Como pode-se observar na fala de um aluno "Sim, seu vocabulário é extenso e compreensivo proporcionando nos a um enorme entendimento".

Nestes casos, relacionamos que professores com didáticas dinâmicas ganham credibilidade perante os alunos, passando a impressão que dominam o conteúdo. Levando-se em consideração os dados coletados, nota-se, principalmente em relação à questão na qual se solicita aos discentes que respondam se gostam das metodologias que o professor de História utiliza, que das 57 respondas, 73\% gostam da maneira como o professor realiza suas aulas, pelas seguintes razões: aulas criativas; domínio de conteúdo; professor dinâmico; e variação das metodologias. Porém, $9 \%$ dos alunos responderam que não gostam da forma como o 
professor realiza suas aulas, pois consideram que aulas são monótonas, sem debates e sem domínio do conteúdo por parte do professor. Os outros $16 \%$ consideram as formas "mais ou menos", porque as aulas de História são chatas; entretanto, há uma compreensão: exige demais, acima da capacidade de entendimento.

Joanilho (1996) afirma que a universidade comete falhas no processo de ensino, o que viria a ocasionar futuras falhas na atuação do profissional. Em contraponto, Paim descreve que "na perspectiva do Fazer-se Professor, entendemos formação como processo continuo, que ocorre ao longo de toda uma vida e não apenas num dado momento ou lugar. Possibilita-nos pensar na incompletude do ser humano e no seu eterno fazer-se". (PAIM, 2007, p. 162).

Ao continuar o raciocínio do autor acima, percebemos que a aprendizagem do professor ocorre tanto no âmbito docente quanto no discente. No meio docente, levando em consideração discussões e reflexões em sala de aula, um dos pontos de pesquisa, constatamos que é um processo de grande valor para a construção de conhecimento. Os recursos didáticos utilizados acabam ficando de lado, em meio às discussões e aos debates, oportunizando o conhecimento do aluno, adquirido por outros meios e espaços, ou do próprio docente, adquirido em toda a sua construção, enriquecendo o processo ensino-aprendizagem.

Constatamos, diante da análise realizada, que boa parte dos discentes classificam-se como seres participativos voluntários, alguns participam somente quando o conteúdo os instiga e uma pequena parte quando é solicitada a participação por parte do professor. Entretanto, a participação em sala de aula passa a ocorrer seja da maneira voluntária, seja da maneira involuntária, colaborando com a aprendizagem.

\section{Importância da História}

Na perspectiva de conhecer a realidade vivida nas escolas, a pesquisa demonstrou a importância da História e a relação com o cotidiano, pois um percentual de $67,31 \%$ dos alunos respondeu que percebe relação entre as 
aulas de história, sua vida e a sociedade atual. Estes alunos consideram que a história atual tem relação com o passado.

Estudar o passado é importante para compreender o presente. Um dos alunos respondeu que "sim, pois na minha vida eu utilizo o que aprendo na aula. E compreendo que a sociedade atual é o 'resultado' de tudo o que aconteceu no passado", enquanto outro escreveu que "sim, porque a história nós vivemos no cotidiano, nós estamos fazendo história".

Por outro lado, esse trabalho revelou também um percentual grande, $23,07 \%$, dos alunos que responderam que não veem relação alguma entre as aulas de história, sua vida e a sociedade atual porque consideram um passado distante, havendo a seguinte resposta: "não, pois estou vivendo a atualidade e história, a gente vive o passado".

Por sua vez, 9,62\% dos alunos questionados responderam que talvez ou geralmente percebam alguma relação entre as aulas de história, sua vida e a sociedade atual, fazendo comparações. Alguns alunos não responderam esta questão.

Com a pesquisa podemos ter uma ideia de quanto esses alunos gostam ou não da disciplina de história, dos conteúdos ou das atividades desenvolvidas em sala de aula e assim serem capaz de fazer uma reflexão crítica sobre os conhecimentos aprendidos.

O pouco interesse pelos conteúdos de história da parte de alguns alunos se dá em virtude dos assuntos estarem longe de sua realidade, assim, eles "vêem o estudo da história como mero acúmulo de informações, nomes e datas do passado, sem relação com sua vida". (FRANCO; VENERA, 2007, p. 75).

Esse mesmo desinteresse é possível observar na pesquisa realizada, em que alguns dos alunos, 1,92\%, disseram que o número de aulas de história deve diminuir para que se produza conhecimento, ou seja, o número de aulas, além de ser baixo e não contribuir para um aprofundamento nos conteúdos, é visto por essa pequena parcela de estudantes como algo desnecessário e distante de sua realidade.

Por outro lado, evidencia-se a valorização das aulas de história quando $48,08 \%$ dos alunos responderam que o número de aulas deve 
continuar como está; 30,77\% dos alunos responderam que nunca pensaram sobre o assunto; $17,31 \%$ dos alunos disseram que as aulas de história devem aumentar para que se produza conhecimento efetivamente.

A partir dessas respostas podemos traçar um perfil do ensino de história no qual observamos que a maioria dos estudantes deseja que o número de aula continue como está, apesar ser bastante reduzido. Portanto, em sua avaliação as aulas de história nem sempre contribuem para produzir novos conhecimentos, ficando em muitos casos apenas num conhecimento superficial, no qual os estudantes, quando concluírem o Ensino Médio, provavelmente não irão lembrar o que estudaram.

Ao serem questionados se estudam história fora da sala de aula, as respostas apresentadas nos fazem refletir a forma com que eles se relacionam com os conteúdos. Assim sendo, 30,77\% dos alunos responderam que não estudam os conteúdos fora da escola, pois consideram os mesmos ultrapassados e desinteressantes, por falta de vontade e de tempo. Por exemplo, como destacou um dos questionados: "não, pois não sobra muito tempo e em si não gosto da matéria"; Já outro respondeu que: "não, porque eu esqueso [sic] de estudar e tenho muita preguiça, mas vou bem nas provas". Outros 9,83\% dos alunos responderam algo semelhante, ou seja, estudam quando necessário, quando têm provas e explicações de trabalhos, portanto, estudam muito pouco.

As respostas evidenciam que o mais importante, para essa parcela de alunos, não é produzir conhecimento para a vida, mas sim tirar notas boas nas provas para passar de ano, se formar conseguir um emprego, ou entrar para uma universidade; outros já estão preocupados com outras tarefas, dizendo que não sobra tempo.

Caberia nesse caso um estudo ampliado para identificar quais seriam essas outras atividades que estão tomando o tempo do jovem estudar. Seria a televisão? O computador? O vídeo game? Os passeios com os amigos? Ou até mesmo o trabalho, que muitos necessitam em virtude de sua condição social?

Um número relativamente pequeno de estudantes, 10,96\%, responderam que ás vezes estuda fora da escola para fazer pesquisas, temas, provas ou quando os conteúdos são interessantes. Podemos tomar como exemplo a 
seguinte resposta: "às vezes, quando tem um conteúdo que eu achei interessante eu procuro na internet ou em revistas para saber mais".

Por outro lado, $48,08 \%$ dos alunos responderam que estudam os conteúdos de história fora da sala de aula, para complementar os assuntos já discutidos, por meio de pesquisas na internet, leituras de livros e revistas. Este pensamento foi expresso da seguinte maneira por um entrevistado: "sim, sempre pesquiso os conteúdos em livros e na internet". Enquanto outro escreveu: "sim, pois deve adquirir um conhecimento maior do que aprendo durante as aulas".

A disciplina de História nem sempre encontra adeptos, seguidores ou entusiastas nos estudantes do Ensino Médio. O maior ou o menor entusiasmo dos alunos depende como os conteúdos são trabalhados, debatidos e qual enfoque teórico-metodológico é dado. Dessa forma, haverá, então, sua compreensão e conseguirão relacioná-la com diferentes aspectos da vida local ou regional, bem como com os conflitos, as questões sociais, econômicas, políticas e culturais que digam respeito a seu mundo cotidiano.

Nesse sentido, a pesquisa demonstrou que $86,54 \%$ dos alunos responderam que percebem importância em estudar história, pois precisam conhecê-la para compreendê-la. Assim, fica marcado na resposta de um entrevistado: "É importante estudarmos para entendermos nossa sociedade atual". Fica destacada a importância do conhecimento, bem como o estudante sentir-se participante do processo de construção desta, levando em consideração diferentes aspectos.

Por sua vez, 7,69\% dos estudantes afirmaram que veem mais ou menos relação ou nem tanto, pois somente algum conhecimento tem importância, como expressa esta resposta: "Em muitos assuntos que estudemos sim, mas em alguns não, porque alguns relatam histórias que nosos [sic] avós falavam para nós". Percebe-se que os estudantes querem conteúdos atuais ou que tenham relações com o momento em que vivem, pois consideram que o passado é algo que não lhes diz respeito ou não conseguem estabelecer relações deste com o mundo atual.

Contudo, 5,77\% dos alunos entrevistados responderam que não veem relação alguma, conforme a seguinte resposta: "A única coisa é que 
agente aprende o que aconteceu no passado, mas não acho muito importante". Isto nos leva a pensar que há alguma relação com a forma do professor trabalhar esses conteúdos. Outro aspecto que deve ser analisado é a conjuntura atual: o mundo das imagens, onde tudo deve ser rápido, imediato, e a busca de retorno quase que instantâneo de resultados que esses jovens buscam.

Percebemos que são poucos os alunos que reservam um tempo para a busca de novas informações, pesquisas, estudos e debates fora da sala de aula. Isto é evidenciado nas respostas de 44,33\% dos estudantes, que afirmaram não discutir com familiares ou amigos assuntos relacionados à história, conforme expresso por um jovem ao afirmar que: "pois eu não fico muito com minha família e meus amigos também não gostam muito de história", ou mesmo por não se interessarem. Outro destaque nas entrevistas é que: "Não, falar sobre o passado é um pouco chato". Porém, entendemos ser possível desconstruir essa ideia e propor uma forma diferente de trabalhar o ensino de História. Nesse sentido, partilhamos da análise de Schmidt (2002), quando sugere que os conteúdos sejam "construídos a partir do entendimento" do que é história para os alunos e "dar sentido ao passado encontra-se na mudança" da forma de saber, pensar e compreender esses conteúdos, assim como a maneira como o professor os trabalha.

Dentre os alunos respondentes, $28,85 \%$ afirmaram que discutem os assuntos de história com pais e amigos, pois consideram o contexto social importante, ou "sempre que o tema, entra em discussão, porque a história além de ampliar conhecimento é muito interessante". Apesar dos estudantes viverem mais o presente, há uma consciência, e até preocupação, em relação ao conhecimento do passado e as influências, positivas ou negativas, destes na atualidade histórica, social, econômica, política e cultural.

Enquanto isto, 26,93\% dos alunos respondeu que discutem o assunto muito pouco, raramente ou às vezes: "às vezes quando aprendo algo interessante, e quero discutir ou compartilhar com alguém". Ou "às vezes questiono meus avós sobre antigamente". Nota-se uma dubiedade nos jovens estudantes do Ensino Médio, pois se por um lado consideram 
importantes os conteúdos de História, por outro somente vão buscar novas fontes quando Ihes interessa determinado assunto.

\section{Algumas Considerações Preliminares}

Ao realizarmos esse trabalho podemos concluir o quanto à educação e o ensino de história são importantes em nossa sociedade. Papel este expresso em muitas das respostas reveladas pela pesquisa desenvolvida com jovens do Ensino Médio das escolas participantes do Programa Universidade-Escola da Unochapecó. As respostas, de certa forma, nos possibilitaram visualizar como poderá ser nosso futuro trabalho como docentes durante o estágio e posteriormente como professores.

Destacamos também como o papel do professor de história é de suma importância para esses jovens, pois estes professores têm em sua mão uma ferramenta especial, quando oportunizam o conhecimento da história, cultura e identidade dos seus alunos.

No geral observou-se através das respostas e durante as aulas assistidas nas escolas que em alguns casos os professores centram-se basicamente no livro didático, o que faz com que o aluno sinta-se pouco motivado, associado a isso alguns alunos questionam a real importância do ensino de história para sua vida em sociedade.

É possível concluir que para os alunos do Ensino Médio, participantes da pesquisa, o estudo é importante por diferentes motivos. Evidencia-se a importância desses alunos estarem querendo um futuro melhor, e vendo a educação como porta de entrada para este futuro.

Deve-se destacar entre os recursos didáticos mais utilizados o livro didático que se observa ser um apoio para o professor nas suas aulas, embora não seja o único instrumento. Entre os recursos podemos destacar a utilização de vídeos, projetor de mídia, mapas, laboratório de informática. Dessa forma, é de suma importância ressalvar que os discentes afirmam estar satisfeitos com as metodologias utilizadas na sala de aula. Outro aspecto a destacar é que o gosto pela disciplina de história está diretamente 
relacionado com as formas didáticas e a maneira como o professor desenvolve a disciplina.

Portanto, podemos concluir que existem muitos desafios para que possamos desenvolver o ensino de História: inicialmente destacamos que é necessário fazer o aluno sentir-se inserido na história e não ser um mero espectador. Em segundo destacamos que, talvez ao começarmos o trabalho pela história local os alunos possam perceber que também produzem história. Em terceiro é fazer com que estes alunos percebam a importância que a história tem para e a sociedade atual, e que ela não é apenas uma narração do passado.

Enfim, ao concluir este trabalho obtivemos dados que nos foram reveladores para o nosso futuro profissional como professores de História, mas em contrapartida nos proporcionou outros importantes questionamentos. Fez-nos pensar na possibilidade de novas pesquisas e trabalhos desenvolvidos com professores, com funcionários das escolas ou em outros ambientes em que esses alunos estejam inseridos. Apontandonos as dificuldades do "fazer-se professor", obtendo-se assim mais informações que nos ajudam a (re)inventar a prática como professores de História que logo chegaremos às escolas.

\section{Referências}

CARVALHO, A. M. P. de. A pesquisa no ensino, sobre o ensino e sobre a reflexão dos professores sobre seus ensinos. Educação e Pesquisa. São Paulo, v.28, n.2, p 57-67, jul./dez. 2002.

BEILLEROT, J. A Pesquisa: Esboço de uma análise. In: ANDRÉ, M. (org.). O papel da pesquisa na formação e na prática dos professores. 3 ed., Campinas, SP: Papirus, 2004. p. 71-90.

BITTERCURT, C. M. F. Ensino de História: fundamentos e métodos. São Paulo: Cortez, 2004.

DEMO, P. Educar pela pesquisa. 3 ed., Campinas; Autores Associados, 1998. 
FRANCO, A. P.; VENERA, R. A. S. A Memória e o Ensino de História Hoje: um desafio nos deslizamentos de sentido. In ZAMBONI, E. (Org.).

Digressões sobre o ensino de História: memória, história oral e razão histórica. Itajaí: Maria do Cais, 2007, p. 73-102.

FREIRE, P. Pedagogia da autonomia: saberes necessários à prática educativa. 15 ed., São Paulo: Paz e Terra, 2001.

HOBSBAWN, E. Era dos extremos: o breve século XX: 1914-1991.2 ed., São Paulo: Cia das Letras, 1995.

JOANILHO, A. L. História e Prática: pesquisa em sala de aula. Campinas SP: Mercado de Letras, 1996.

LENOIR, Y. Pesquisar e formar: repensar o lugar e a função da prática de ensino. Educação e Sociedade. Campinas v.27, n.97, p.1075-1402, set./dez. 2006.

MONTEIRO, A. M. F. da C. Ensino de História: entre saberes e práticas. Tese (Doutorado em Educação) Departamento de Educação, PUC - Rio de Janeiro, Rio de Janeiro, 2002.

PAIM, E. A. Do formar-se ou fazer-se professor. In. MONTEIRO, A. M.; GASPARELLO, A. M.; MAGALHÃES, M. (Org.). Ensino de História: Sujeitos, saberes e práticas. Rio de Janeiro: Mauad X: Faperj, 2007.

SCHMIDT, M. A. Jovens brasileiros e europeus: identidade, cultura e ensino de história (1998-2000). Revista Perspectiva. Florianópolis, v. 20, n. Especial, jul./dez. 2002. p. 182-208. 